\title{
RESPONSABILIDADE SOCIAL E HOSPITALIDADE: Um Estudo sobre o Apoio de Empresas a Projectos Culturais.
}

\author{
Autor. \\ VALMIR MARTINS DE OLIVEIRA \\ Doctorando en Estudios Internacionales (USACH, Chile) \\ Magíster en Hospitalidad - Universidade Anhembi-Morumbi (Brasil) \\ Master en Turismo - Universidade de São Paulo (Brasil) \\ Profesor Carrera de Turismo y Hotelería en Universidad de las Américas (Chile) y Universidade Cruzeiro do
}

Sul (Brasil)

\section{RESUMEN}

Este estudio tiene el objetivo de analizar como las formas de apoyo a proyectos culturales pueden componer la estrategia de responsabilidad social de las empresas bajo la óptica del marketing de relación y hospitalidad. En este sentido, fueron seleccionados los principales aspectos que evidencian las políticas de responsabilidad social, a fin de permitir un análisis sobre la relación de estos con el apoyo a proyectos culturales para actuales y potenciales clientes, así como para comunidades. Con base en la estructuración de una proposición teórica y la identificación de las variables orientadoras de la investigación, fue realizado un estudio de caso sobre la actuación de la empresa American Express de Brasil. Los resultados del estudio revelaron el posicionamiento empresarial relacionado al establecimiento de vínculos con públicos estratégicos, fortaleciendo una imagen corporativa de responsabilidad social, preservación del patrimonio histórico y promoción turística. También sugieren que las relaciones empresariales con entidades del Tercero Sector forman alianzas estratégicas en la conducción de proyectos sociales y culturales.

Palabras-Clave: Hospitalidad. Responsabilidad Social Empresarial. Proyectos Culturales. Marketing de Relación. Marketing Cultural. 


\section{ABSTRACT}

This study has the objective to analyze as the support forms to cultural projects can compose the strategy of social responsibility of the companies under the optics of the relationship marketing and hospitality. In this direction, main aspects had been selected that put evidence to the politics of social responsibility, in order to allow an analysis about the relationship of these with the support of cultural projects for current and potential customers, as well as for communities. On the basis of a theoretical proposal structure and the identification of the orienting variable of the research, were carried through to a study case on the performance of the American Express do Brasil company. The study results had disclosed the related enterprise positioning to the establishment of bonds with strategical public, fortifying a corporative image of social responsibility, preservation of the historical patrimony and tourist promotion. They also suggest that the enterprise relations with entities of Third Sector form strategical alliances in the conduction of social and cultural projects.

Keywords: Hospitality. Business Social Responsibility. Cultural Projects. Relationship Marketing. Cultural Marketing.

\section{RESUMO}

Este estudo tem o objetivo de analisar como as formas de apoio a projetos culturais podem compor a estratégia de responsabilidade social das empresas, sob a ótica do marketing de relacionamento e hospitalidade. Nesse sentido, foram selecionados os principais aspectos que evidenciam as políticas de responsabilidade social, a fim de permitir uma análise sobre o relacionamento destes com o apoio a projetos culturais, para atuais e potenciais clientes, bem como para comunidades. Com base na estruturação de uma proposição teórica e a identificação das variáveis norteadoras da pesquisa, foi realizado um estudo de caso sobre a atuação da empresa American Express do Brasil. Os resultados do estudo revelaram o posicionamento empresarial relacionado ao estabelecimento de vínculos com públicos estratégicos, fortalecendo uma imagem corporativa de responsabilidade social, preservação de patrimônio histórico e promoção turística. Eles também sugerem que as relações empresariais com entidades do Terceiro Setor formam alianças estratégicas, na condução de projetos sociais e culturais.

Palavras-chave: Hospitalidade. Responsabilidade Social Empresarial. Projetos Culturais. Marketing de Relacionamento. Marketing Cultural. 


\section{Objetivos}

A incorporação de políticas de responsabilidade social nas diretrizes empresariais vem ao encontro das grandes transformações da gestão empresarial, que contribuem para um melhor posicionamento mercadológico frente aos clientes, atuais e potenciais e às comunidades que são afetadas direta ou indiretamente por seus negócios. Um estudo que permite conhecer com maior propriedade as estratégias empresariais de responsabilidade social, com foco no apoio a projetos culturais, torna-se necessário o entendimento sobre as influências que tais políticas e ferramentas afetam na dinâmica empresarial. Nesse sentido, o apoio a projetos culturais deve ser analisado com propriedade e também como a sua contribuição pode afetar o relacionamento da empresa com a comunidade, participando do processo de desenvolvimento sociocultural e turístico, relacionado à hospitalidade e marketing cultural.

O objetivo do estudo não é chegar num consenso ou conceitos universais, pois a estratégia e criatividade de cada empresa têm um papel fundamental para o seu posicionamento exclusivo e competitivo, porém, é analisar como os níveis de comprometimento e relacionamento geram ações e retornos no ambiente empresarial em que opera. Para tanto, o objetivo do presente estudo concentra-se na identificação e análise das formas de apoio a projetos culturais podem compor a estratégia de políticas de responsabilidade social.

\section{Visão estratégia de responsabilidade social empresarial}

Segundo a World Business Council for Sustainable Development (WBCSD), responsabilidade social é o comprometimento permanente dos empresários, em adotar um comportamento ético e contribuir para o desenvolvimento econômico simultaneamente, melhorando a qualidade de vida de seus empregados e de suas famílias, da comunidade local e da sociedade como um todo (Almeida, 2002).

A dimensão da questão da responsabilidade social está relacionada a diferentes idéias que, para algumas empresas, pode significar a ética frente aos negócios; para outras, o cumprimento de leis que regem o seu negócio, como também contribuições sociais de forma voluntária, para causas específicas.

A nova realidade do mercado, marcada pelo aumento da complexidade nos negócios, principalmente em decorrência dos processos de globalização e da velocidade 
Cabe salientar que o crescente cenário de desigualdades sociais obrigou a repensar os modelos de desenvolvimento econômico, social e ambiental, levando a uma cobrança do posicionamento da empresa, frente a essas questões, organizando-se com o poder público e representantes das comunidades onde opera, para trazer respostas que seguem na direção de um modelo de desenvolvimento sustentável. Diante deste cenário, a cultura da responsabilidade social empresarial começa ser inserida neste cenário.

O marco precursor, nos estudos científicos sobre o tema de responsabilidade social, foi por meio da obra Responsibilities of the Businessman, de Howard Bowen, publicada em 1953, nos Estados Unidos. No discurso de Bowen, os administradores das empresas têm o dever moral de implementar políticas, tomar decisões e seguir linhas de ação que sejam desejáveis aos anseios e valores da sociedade. De outra parte, os críticos ressaltavam que a responsabilidade social partia da escolha dos dirigentes, de acordo com as suas próprias idéias.

Essa posição foi ratificada, pelo economista Milton Friedman, cuja análise da responsabilidade social se concentra no uso de recursos e energia em decisões para aumentar os lucros, reforçando o papel da empresa na produção de bens e serviços e que os problemas sociais cabem aos órgãos governamentais competentes (Stoner y Freeman, 1991).

Em síntese, o discurso da responsabilidade social remete também para a reatividade social das empresas e compõe duas abordagens básicas: a primeira é defendida por Robert Ackerman (idem) que presume que a empresa passa por três fases, para reagir às questões sociais: na primeira fase, o dirigente reconhece a existência de um problema social e o torna público; na segunda fase, parte para a contratação de especialistas para assessorá-la e propor soluções; a terceira e última fase é a implementação das ações e sua incorporação na gestão empresarial.

Por outro lado, considerando uma análise de nível macro, a segunda abordagem consiste nos estudos realizados por Lee Preston e James Post (apud Stoner y Freeman, 1991), para analisar a reatividade das empresas sob dois modos distintos: as relações primárias que envolvem os funcionários, clientes, acionistas e credores; vale ressaltar que essas relações estão entrelaçadas por interesses mercadológicos. E as relações secundárias, que remetem para os aspectos ligados às leis e à moralidade, tendo o governo e a opinião públicos fortemente destacados, na ação.

Para a teoria de desempenho social da empresa, proposta por Carroll (apud Stoner y Freeman, 1991) como demonstra a Figura N $\mathrm{N}^{\mathrm{0}}$ 1, a combinação dessas duas abordagens amplia o posicionamento da empresa e analisa as limitações, ou seja, as empresas devem ser reativas a todas as demandas sociais? O contraponto seria a ação em casos e momentos específicos? 
Figura $\mathrm{N}^{\mathrm{o}} 1$ - A teoria da reatividade social das empresas

\begin{tabular}{|c|c|c|}
\hline $\begin{array}{c}\text { Modelo de Ackerman } \\
\text { A reação de uma empresa a uma questão } \\
\text { social } \\
\text { desenvolve-se em três fases }\end{array}$ & $\begin{array}{r}\text { Modelo de Preston e Post } \\
\text { O governo e a opinião pública fixam os } \\
\text { limites dos relacionamentos primários e } \\
\text { secundários da empresa com a sociedade }\end{array}$ \\
\hline Análise de nível micro Análise de nível macro \\
\cline { 2 - 3 } & $\begin{array}{c}\text { Os princípios econômicos legais e éticos criam um } \\
\text { «contrato social» entre empresas e sociedade. } \\
\text { O contrato social é implementado nas decisões } \\
\text { reativas, defensivas ou pró-ativas da empresa. } \\
\text { (Combina as análises do micro e macro) }\end{array}$ \\
\hline
\end{tabular}

Fonte: Stoner y Freeman 1991, Pág. 74

Para ser compreendida e aceita pelos dirigentes de empresas, Carroll (1991) defende que a responsabilidade social empresarial deve ser estruturada de uma forma que permeie todas as esferas de responsabilidade que o negócio envolve, e propõe a Pirâmide da Responsabilidade Social Empresarial.

Sob essa ótica, propôs o posicionamento da empresa na dimensão de tipos de responsabilidades sociais: econômico, legal, ético e filantrópico, conforme Figura 2:

Figura $\mathrm{N}^{\mathrm{o}} 2$ - A pirâmide da responsabilidade social empresarial

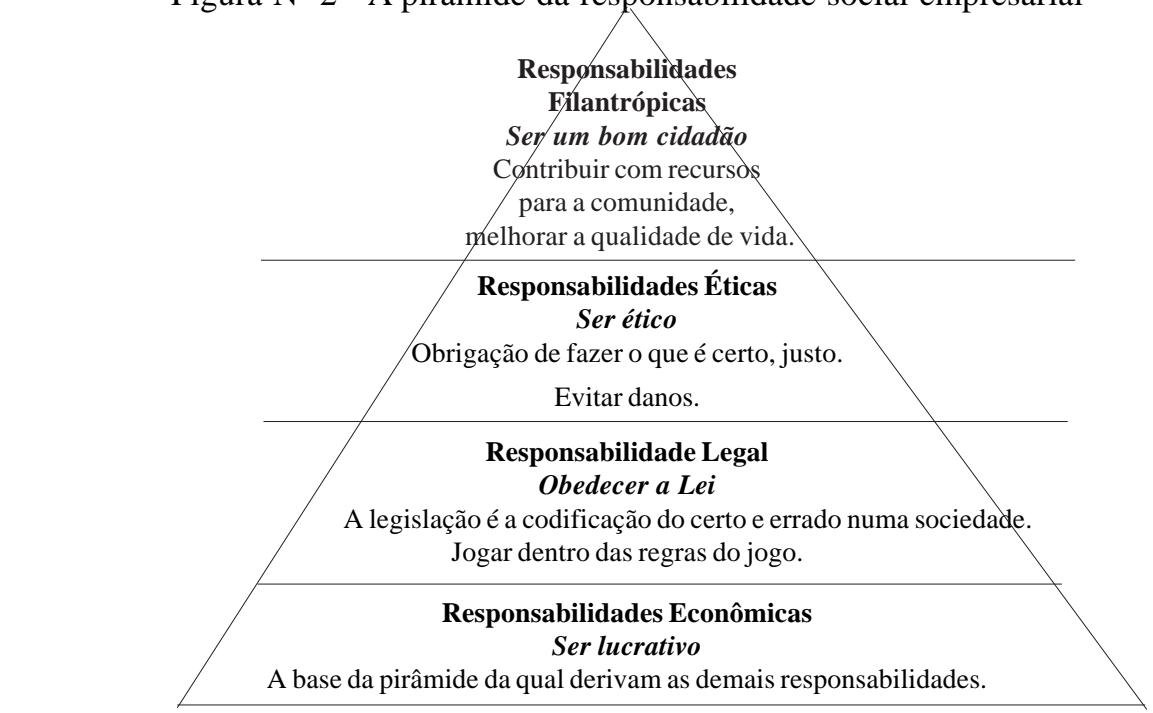

Fonte: Carroll (1991, Pág.4) 
As responsabilidades econômicas partem do princípio de que as organizações foram criadas historicamente como entidades econômicas, como negócios que oferecem bens e serviços para a comunidade e atendem às suas necessidades, dentro de um parâmetro de lucro aceitável. O objetivo econômico surge como um incentivo para o crescimento do empreendimento, porém, em determinado momento, para maximização dos lucros. Carroll (1991) também ressalta que todas as responsabilidades restantes do negócio são prejudicadas na ausência das responsabilidades econômicas, pois, sem elas, as demais se tornam considerações discutíveis.

A análise sobre as responsabilidades legais considera que além do negócio ser motivado pelo lucro, espera-se que a empresa cumpra com as leis e os regulamentos promulgados nos âmbitos: federal, estadual e local. Desse papel das empresas na sociedade, espera-se que possam seguir seus objetivos dentro da estrutura da lei.

Sobre as responsabilidades éticas, destacam-se as atividades e práticas que são esperadas e/ou proibidas pela sociedade, mesmo que não previstas na lei. As responsabilidades éticas incluem os padrões, normas ou expectativas que refletem um interesse social e que a comunidade considera como ação justa, conforme os direitos morais dos stakeholders.

Segundo Costa (2004, p.89), stakeholder pode ser definido como:

[...] qualquer instituição, pessoa, grupo de pessoas, formal ou informal que tenha algum tipo de interesse que pode afetar ou ser afetado pelo funcionamento, operação, comercialização, desempenho, resultados, presentes ou futuros da organização em questão.

Por um lado, mudanças sobre ética e valores precedem o estabelecimento de leis, pois eles se tornam a força propulsora para a criação de novas leis. Por exemplo, a questão do meio ambiente, direitos humanos e movimentos dos consumidores repercutem na alteração dos valores da sociedade, alterando padrões e referências, tornando a legislação ultrapassada.

Entretanto, as responsabilidades éticas podem ser vistas por meio de valores emergentes das normas e do que a sociedade espera do negócio, refletindo num padrão de desempenho mais elevado do que aquele requerido atualmente pela lei. Deve também apresentar um constante debate público, para que sejam reavaliadas a respeito da sua legitimidade, de forma que os negócios não tenham dificuldades em lidar com as mesmas. O movimento de ética empresarial estabeleceu-se concretamente como um componente legítimo da Responsabilidade Social Empresarial. No topo da pirâmide, considera-se as 
responsabilidades filantrópicas a resposta à expectativa da sociedade, para que os negócios sejam benéficos para o cidadão. Nessa perspectiva, permite a concepção de programas de promoção do bem-estar humano, envolvendo uma atuação efetiva da empresa, com recursos financeiros e econômicos, prestando uma contribuição para as artes, educação e comunidade.

A característica que distingue entre responsabilidades filantrópica e ética, é que da primeira não se espera um sentido ético ou moral. As comunidades desejam contribuições financeiras, facilidades e tempo do empregado aos programas sociais, mas não consideram um ato antiético se não corresponderem ao nível desejado. Dessa forma, expressa um desejo dos dirigentes ou da corporação de engajar-se em projetos sociais.

Carroll (1991) descreve também que algumas empresas sentem que estão sendo socialmente responsáveis, se forem apenas bons cidadãos na comunidade. Essa abordagem representa um aspecto vital na Responsabilidade Social Empresarial, porém não se limita a ela.

Torna-se necessária uma análise com profundidade sobre o contexto em que a empresa atua com os seus negócios, partindo do próprio perfil de negócio, cenário econômico, social e legal em que atua e a partir de uma visão plena das suas potencialidades e vulnerabilidade, é possível traçar um plano de ação junto ao mercado cultural, tornando a intervenção da empresa mais relevante (CORRÊA, 2004).

Com relação ao marketing cultural, segundo Muylaert (1993, p.27), é «o conjunto de recursos de marketing que permite projetar a imagem de uma empresa ou entidade através de ações culturais».

Já Machado Neto (2002, p.169) busca uma definição mais crítica sobre marketing cultural e suas interfaces sociais como «a atividade deliberada de viabilização físicofinanceira de produtos e serviços culturais, comercializados ou franqueados, que venham a atender às demandas de fruição e enriquecimento cultural da sociedade.»

O investimento privado em atividades artístico-culturais, além de promover o resgate e valorização da cultura, estabelece um valor agregado às ações de comunicação empresarial. Esses fatores são essenciais também para o desenvolvimento de um ambiente de criação e manutenção de vínculos com a sociedade.

\section{Hospitalidade e realização de projetos culturais}

Com o objetivo de satisfazer a necessidade de presença de outro ser humano é que se desenvolvem as formas de sociabilidade e a hospitalidade, conforme destaca 
Praxedes (2004)

A vida humana depende da ação dos indivíduos e de sua interação. O ser humano é um ser portador de necessidades que só se realizam através dos relacionamentos entre os humanos. O reconhecimento de um outro ser como humano implica em reconhecermos as suas necessidades de recursos materiais, bens simbólicos e da presença de outro ser humano. Para a satisfação desses três conjuntos de necessidades elementares é que se desenvolvem as mais diferentes formas de interação e relacionamento afetivo, de elaboração de conhecimentos, de atividades lúdicas e artísticas, e de produção de bens e serviços.

Segundo Lima, no âmbito analítico operacional, a hospitalidade pode ser definida: «[...] como o ato humano, exercido em contexto doméstico, público ou profissional, de recepcionar, hospedar, alimentar e entreter pessoas temporariamente deslocadas de seu hábitat» (2003, p. 19).

A hospitalidade, no âmbito das organizações, tende a promover um estreito relacionamento entre a empresa e o atendimento às expectativas da sociedade. Dentro dessa perspectiva, a dinâmica da gestão empresarial é ampliada, conforme Freitas (2004, p. 1) descreve:

A finalidade do planejamento não deve restringir a organização do setor para atender apenas às necessidades do mercado (tendo como objetivo o crescimento econômico baseado no lucro), mas ultrapassar a dimensão econômica avançando no social, contemplando relações de confiança e solidariedade, de comprometimento e reciprocidade, em busca da hospitalidade (tendo como objetivo o interesse comum).

Partindo do princípio de que as diretrizes de responsabilidade social buscam promover uma maior aproximação da empresa com a comunidade, por meio do entendimento das suas necessidades sociais que cercam a organização, tal relação é primordial para proporcionar um ambiente de convivência mais harmonioso, conforme já assinalado por Gotman (2001 p.493): «A hospitalidade é um processo de agregação do outro à comunidade e a inospitalidade é o processo inverso».

Torna-se provável que, nessa análise, a essência da dádiva existente na responsabilidade social das empresas e ações que podem servir para o desenvolvimento socioeconômico de comunidades, «seja ou não precedido de um convite ou um pedido de 
ajuda, numa perspectiva de vínculo social» (Lima, 2004, p.19).

No Brasil, o programa é desenvolvido pela Academia de Viagens e Turismo (AVT) que, em parceria com a Universidade de São Paulo (USP), desde 1993, já formou mais de 6.000 estudantes, treinou 1.000 professores aproximadamente e, mais de 5.000 pessoas participaram dos seus workshops. Em 2005, mais de 5.000 jovens matricularam-se nos cursos da AVT-Brasil.

Herança cultural: $O$ terceiro foco de atuação abrange a recuperação de monumentos históricos mundiais, de relevância cultural e turística.

Exemplo disso, em 1995, a American Express desenvolveu, com a organização não-governamental World Monuments Fund (WMF), da qual a ela é sócio-fundadora, o programa World Monuments Watch (WMW), com o objetivo de investir anualmente, na preservação de cem monumentos em risco, no mundo. Os projetos recebidos são enviados diretamente por comunidades representadas por institutos, associações, entidades privadas e pelo poder público.

A WMF seleciona anualmente os projetos por intermédio de uma equipe técnica, que contempla: arqueólogos, historiadores, geólogos, dentre outras especialidades, que entram numa lista de propostas e, quando se tornam pré-selecionados, é solicitada uma relação de documentos que reafirma a autenticidade e necessidade.

O projeto da Vila de Paranapiacaba ${ }^{1}$ foi contemplado na lista de 2000 e 2003, com aporte de cento e cinqüenta mil dólares, com enfoque para a preservação e restauro do patrimônio. Teve como objetivo incrementar o turismo na região, fortalecer a cultura e estimular a comunidade, para que trabalhe o entorno. Sua vila ferroviária, ao estilo inglês, foi construída em meados da metade do século XIX e foi o sistema ferroviário explorado pelo grupo São Paulo Railway.

Teve seu patrimônio arquitetônico, tecnológico e seu entorno, compostos por remanescentes da Mata Atlântica; foram tombados, em 1987, pelo Conselho de Defesa do Patrimônio Histórico Artístico, Arqueológico e Turístico do Estado de São Paulo (CONDEPHAAT). Atualmente, existem processos de reconhecimento municipal e nacional, pelo Instituto Patrimônio Histórico Nacional (IPHAN), como patrimônio cultural. Em 2000, foi selecionado o projeto de restauração da Casa Fox e envolveu a quantia de US\$50 mil.

Já em 2003, foi a vez do projeto do Museu Castelinho, no Centro de Preservação de Paranapiacaba, que foi a residência do engenheiro-chefe da São Paulo Railway. Construída em 1897, é a maior casa da Vila, possui janelas que fornecem

${ }^{1}$ Localizada no município de Santo André, Estado de São Paulo 
visão panorâmica da mesma e abriga peças da ferrovia. Essa obra recebeu recursos na ordem de 100 mil dólares. O projeto também envolveu a digitalização de documentos históricos e um plano de desenvolvimento turístico.

Essa abordagem é profundamente explorada por Godbout (1999, p. 29) na sua análise crítica sobre as referências de Marcel Mauss e explora o universo que envolve a dádiva como a criação, alimentação ou recriação de vínculos sociais por meio da oferta de bens ou prestação de serviços e essencialmente onde não há garantia de retorno. Godbout também ressalta que a dádiva está a serviço do vínculo; ela não é todo o vínculo.

Contudo, entender a intervenção da empresa no cenário de desigualdade social remete para o fenômeno da reciprocidade, onde se espera um reconhecimento da comunidade pela ação realizada. Essa retribuição esperada torna-se uma legitimidade na consolidação da imagem da empresa, como integrante e atuante no seu papel social.

Tomando a hospitalidade como uma referência no estabelecimento de vínculos sociais, a realização de projetos culturais permite uma aproximação da empresa com comunidades, sejam elas constituídas por clientes ou não de seus produtos e serviços, integrando-a ao contexto social em que está inserida.

É essencial que seja evidenciado o papel das instituições sociais como entidades filantrópicas, entidades de direito civil, movimentos sociais, organizações nãogovernamentais (ONGs), agências de desenvolvimento social e institutos sociais de empresas.

Nesse sentido, o projeto cultural contribui para potencializar o composto de comunicação da marca da empresa que necessita refletir atitudes e mudanças de comportamento. Ao lidar com a cultura, estão envolvidos valores, emoções, sentimentos e especialmente a identificação, o que pode ser considerado um ponto estratégico nas relações da empresa com o mercado.

Porém, é preciso o estabelecimento de um diálogo com a comunidade e suas diversidades culturais, na busca da conexão com o seu imaginário e valores que são peculiares à mesma. Essa dimensão cultural estrutura uma plataforma de desenvolvimento, com o objetivo de fortalecer valores éticos, prosperidade, sustentabilidade e coexistência global; além do fato de que a comunidade consumidora vem avançando no entendimento baseado na empresa, que tem o dever de contribuir para enfrentar os problemas sociais e que promovam um desenvolvimento sustentável. 


\section{Metodologia}

Contempla a utilização de variáveis relacionadas ao tema, com um descritivo que consolida a abordagem teórica de autores e contribui para uma análise mais consistente, prevista no planejamento da pesquisa. O questionamento norteador da investigação parte de como o apoio de empresas a projetos culturais pode contribuir para fortalecer os relacionamentos das empresas com a sociedade, com base nos pressupostos da responsabilidade social empresarial e da hospitalidade.

Foi selecionada a empresa American Express do Brasil ${ }^{2}$ como estudo de caso, com a respectiva sede localizada no município de São Paulo, que possui políticas de responsabilidade social definidas, com enfoque para o apoio de projetos culturais, tanto para clientes como para as comunidades onde não atua diretamente.

Por outro lado, a American Express por meio dos seus serviços financeiros de cartão de crédito e travelers cheques, está presente em diversos negócios ligados à hospitalidade comercial e turismo, tais como hotéis, restaurantes, agências de viagens, companhias aéreas, locadoras de veículos, câmbio, dentre outros.

Foram efetivados levantamentos documentais impressos e eletrônicos, entrevistas, publicações relacionadas e entidades ligadas ao tema de responsabilidade social, que contemplavam a atuação da American Express.

\section{Estudo de caso: American Express do Brasil S.A.}

Sua história tem início nos Estados Unidos, mais precisamente em Búfalo, no ano de 1850. Os amigos Henry Wells, William G. Fargo e John Butterfield criaram uma empresa de serviço expresso, inicialmente com transporte de cargas e valores, na região oeste dos Estados Unidos, pois se tratava de uma região deserta e poucos se aventuraram, pois existiam muitos índios e roubos; mais tarde, 40 anos depois, incorporando-se produtos financeiros como: ordens de pagamento e travelers cheques.

Atualmente o Grupo American Express é empregador de mais de 65 mil funcionários, sendo que 2.300 estão no Brasil. Emissora de cartões em mais de 52 países, com seus cartões aceitos em mais de 175 deles.

A American Express, por meio da sua fundação, considera que todas as áreas são importantes, para exercer a responsabilidade social externa. Porém, tornou-se necessário estabelecer três áreas estratégicas de atuação, junto às comunidades, compondo assim a sua política:

\footnotetext{
${ }^{2}$ Empresa de serviços financeiros
} 
Serviços comunitários: O primeiro foco está relacionado à cidadania; são todos os programas relacionados aos funcionários e à comunidade em geral.

Independência econômica: $\mathrm{O}$ objetivo do programa é respaldar iniciativas que propiciem, desenvolvam e sustentem a independência econômica de alunos do ensino médio, para ajudá-los a ingressar no mercado de trabalho, por meio de cursos profissionalizantes, na área de Turismo.

Na percepção da AMEX, as entidades estão num processo evolutivo de profissionalização e fortalecimento de parcerias com comunidades, sendo que esses aspectos beneficiam os relacionamentos estabelecidos. (GRAYSON y HODGES, 2003).

Na visão da empresa, o apoio ao projeto de restauração de patrimônios na Vila de Paranapiacaba reforça a relevância da conservação do patrimônio cultural, que traz resultados sociais, políticos e econômicos para a comunidade. Nesse exemplo de apoio, a empresa sinalizou que é vital esse tipo de ação, inclusive para o incremento da atividade turística e o bem-estar da comunidade residente no local, tornando evidente a postura da empresa, de forma convergente às proposições de Melo Neto (2002) e Bastos (2004), sobre essa abordagem social.

A postura da AMEX sinaliza que está mais voltada para o retorno social propriamente dito, como um processo que não tenha tais objetivos específicos de retorno, mesmo que eles se tornem realidade de alguma forma. A empresa acredita no reconhecimento da comunidade, sem estabelecer ações de propaganda. Se o projeto tem o objetivo de projeção da imagem da marca, ele é considerado uma ação de marketing e os recursos não podem ser oriundos da Fundação American Express e sim da verba da área de marketing para esse fim e ações ligadas à área comercial.

Esse posicionamento da empresa diverge da proposição teórica defendida por Melo Neto e Froes (1999) e Kaplan e Norton (2004), voltada para as diretrizes de responsabilidade social externa, que prevê o interesse de visibilidade da empresa nos retornos de imagem, publicitários e para os acionistas.

Por outro lado, a AMEX demonstra uma preocupação no alinhamento dos investimentos em pessoas e capital organizacional para que exerçam um impacto significativo nas suas diretrizes de responsabilidade social.

O estabelecimento de parcerias com entidades do terceiro setor, como a WMF e demais entidades sociais citadas, reforça a necessidade de associar-se com outros agentes de intervenção, com uma atuação direta nas diretrizes das ações. (KAPLAN y NORTON, 2004). 
Esse ponto de vista mostra que a empresa entende que não é a sua atribuição principal a operacionalização dos projetos sociais, cabendo às entidades parceiras esse papel. A empresa demonstra que essa postura não a exime de participar das ações desde a sua concepção, implementação e avaliação de resultados, oferecendo o seu conhecimento, em alguns casos a sua infraestrutura. Existe um interesse especial para projetos que promovam autonomia e sustentabilidade das ações.

Com base na análise das práticas da AMEX, percebe-se que a empresa acredita que os apoios a projetos sociais e culturais (artes cênicas e música considerados pela empresa como marketing cultural, principalmente porque são apoiados por leis de incentivo à cultura) são efetivamente consolidadores de uma estratégia de relacionamento. Porém, na prática, são ações pontuais.

Vale ressaltar que o apoio a projetos de recuperação de patrimônio, em parceira com a WMF, restringe-se a ações pontuais para as comunidades e não é configurado como marketing cultural e relacionamento pela empresa, pois não utilizam verba de publicidade e sim os recursos destinados à operacionalização das diretrizes de responsabilidade social.

A falta de um monitoramento de pesquisa de imagem corporativa, que investe em projetos culturais, pode afetar a sua real compreensão sobre o retorno esperado e quais valores efetivamente são disseminados e percebidos pelo seu público-alvo (GRÖNROOS, 2003 y REIS, 2003).

Na American Express do Brasil, as leis de incentivo à cultura são utilizadas para apoiar projetos que beneficiem principalmente os clientes associados e se estendam para funcionários e a comunidade.

Esses patrocínios configuram que a empresa tem uma preferência pela área de música e artes cênicas, dentro dos segmentos culturais investidos. A área de Marketing é responsável por esse tipo de apoio, com o envolvimento da área de Relações Públicas, de forma co-responsável, na aprovação para as propostas apresentadas, ou seja, o conhecimento da empresa sobre responsabilidade social também interfere nas ações de marketing cultural e de relacionamento.

Numa análise comparativa entre as motivações destacadas por Fischer (2002), a empresa se enquadra nas motivações institucionais e, principalmente, mercadológicas, quando existe o apoio pontual de projetos culturais por meio de leis de incentivo à cultura. Há um entendimento que essa prática é para fortalecer o valor do vínculo com os clientes, apesar de, em alguns casos, essas ações serem estendidas para entidades parceiras do terceiro setor. 
Reforça-se a política de não vincular tais ações com interesses mercadológicos e reforço da imagem corporativa. Exemplo dessa atuação são os projetos apoiados em parceria com o WMF.

Frente a essas questões, ao realizar uma análise sobre hospitalidade, mais especificamente a dádiva envolvida na ação social e cultural para a comunidade, quando ela não é percebida como um ciclo (tríplice dar-receber-retribuir) e sim como um ato isolado, pode provocar um sensação de incompreensão por parte dos indivíduos e, conseqüentemente, a possibilidade de afetar o processo de reconhecimento (retorno) da ação empresarial (Godbout, 1999).

\section{Conclusões}

Dentro do discurso de responsabilidade social empresarial, o estudo de caso permitiu efetuar algumas análises da dinâmica empresarial da empresa American Express do Brasil e suas relações com as proposições teóricas discutidas na revisão bibliográfica.

Considerando, por um lado, a evidência da sua concepção organizacional sobre atuação social e por outro a complexidade que o tema suscita, por envolver diversos atores, neste estudo classificados como stakeholders, foi possível elucidar atitudes que envolvem a criação e manutenção de relações da empresa com os seus públicos estratégicos, no ambiente externo e interno, com enfoque para os projetos culturais.

Os investimentos de empresas em comunidades necessitam de avaliação dos resultados, quantitativos e qualitativos, alcançados por meio de mecanismos de avaliação dos investimentos sociais, com base no desempenho. Percebe-se que esse movimento encontra-se ainda nos primeiros estágios e a tendência é uma maior transparência das suas ações junto à sociedade.

Ao fazer determinadas escolhas, organizá-las e fazer uso delas, com objetivos maiores do que o espectro de alcance de cada ação individual, a empresa demonstra ao seu público sua postura, suas crenças, sua forma de entender e interagir em todas as esferas da sociedade.

Os resultados do estudo de caso permitem sugerir algumas recomendações para as diretrizes de responsabilidade social:

- Criar, manter e fortalecer o vínculo e o canal de interlocução entre empresa e comunidade, de forma que os projetos sejam planejados e implementados sob a gestão de co-responsabilidade, com objetivos de desenvolvimento cultural e promoção turística; 
- Potencializar as relações com entidades do terceiro setor, que contemplem, nos seus projetos, propostas estruturadas de intervenções sociais, legitimadas pela comunidade a ser beneficiada;

- Acompanhar, sistematicamente, a implementação integral do projeto, especialmente no tocante ao retorno que traz para a imagem e posicionamento junto aos stakeholders;

- Buscar a integração dos projetos culturais a programas que envolvam problemáticas sociais em outras áreas, como: educação, saúde, esporte, sustentabilidade econômica, turismo, dentre outros.

As análises e considerações do estudo de caso vêm ao encontro da recomendação para futuros estudos, no sentido de avançar na geração de conhecimento sobre o tema de estabelecimento de vínculos com públicos estratégicos da empresa, por meio de apoio a projetos culturais, numa pesquisa empírica mais abrangente, junto a um universo maior de empresas, contemplando análise de variáveis relacionadas às práticas e dinâmicas dos produtores, entidades do terceiro setor, poder público e comunidades beneficiadas

\section{BIBLIOGRAFIA}

D Almeida, Fernando. O bom negócio da sustentabilidade. Rio de Janeiro: Nova Fronteira, 2002. 191 p. ISBN: 8520912664

$>$ Bastos, Sênia. Patrimônio cultural e hospitalidade: subsídios ao planejamento turístico. En: FREITAS Maneti Dencker, Ada (Coord.). Planejamento e gestão em turismo e hospitalidade. São Paulo: Pioneira Thomson Learning, 2004. pp. 75-91. ISBN: 8522103428.

$>$ Carroll, Archie. [en línea]: The pyramid of corporate social responsibility: toward the moral management of organizational stakeholders. Business Horizons, July-August, 1991[fecha de consulta: 19 febrero 2006]. Disponible en: http://www.findarticles.com/p/articles/mi_m1038/is_n4_v34/ai_11000639

$>$ Correa, Marcos B. Do marketing ao desenvolvimento cultural: relacionamento entre empresas e cultura: reflexões e experiências. Belo Horizonte: Rona, 2004. 87 p. ISBN: 8590422313.

$>$ Costa, Eliezer Arantes. Gestão estratégica. São Paulo: Saraiva, 2004. ISBN: 8502035568.

> Fischer, Micky. Marketing cultural: legislação, planejamento e exemplos práticos. São Paulo: Global, 2002. 120 p. ISBN: 8526007556. 
> Fonseca Reis, Ana Carla. Marketing cultural e financiamento da cultura: teoria e prática em um estudo internacional comparado. São Paulo: Pioneira Thomson Learning, 2003. 313 p. ISBN: 8522103054.

$>$ Freitas Maneti Dencker, Ada (Coord.). Planejamento e gestão em turismo e hospitalidade. São Paulo: Pioneira Thomson Learning, 2004. 199 p. ISBN: 8522103428.

$>$ Gotman, Anne. Le sens de l'hospitalité: Essai sur les fondements sociaux de l'accueil de l'autre. Paris: Presses Universitaires de France, 2001. 493 p. ISBN : 2130514960

> Grayson, David; Hodges, Adrian. Compromisso social e gestão empresarial. São Paulo: Publifolha, 2003. 390 p. ISBN: 1874719837.

> Grönoos, Christian. Marketing: gerenciamento e serviços. Rio de Janeiro: Elsevier, 2003. 404 p. ISBN: 8535212590.

> Kaplan, Robert; Norton, David. Mapas estratégicos - balanced scorecard: convertendo ativos tangíveis em resultados intangíveis. Rio de Janeiro: Elsevier, 2004. 504 p. ISBN: 853521268X.

$>$ Lima Camargo, Luiz Octávio. Hospitalidade. São Paulo: Aleph, 2004. 94 p. ISBN: 8585887974.

$>$ Lima Camargo, Luiz Octávio. Os domínios da hospitalidade. En: FREITAS Maneti Dencker, Ada, SIQUEIRA Bueno, Marielys (org.). Hospitalidade: cenários e oportunidades. São Paulo: Pioneira Thomson Learning, 2003. 148p. ISBN: 8522103984.

> Marcondes Machado Neto, Manoel . Marketing cultural: das práticas à teoria. Rio de Janeiro: Ciência Moderna, 2002. 336 p. ISBN: 8573934638.

$>$ Melo Neto, Francisco Paulo. Evento de ação, entretenimento e agente de promoção do patrimônio histórico-cultural. En: FUNARI, Pedro Paulo; PINSKY, Jaime (orgs.). Turismo e patrimônio cultural. 2. ed. São Paulo: Contexto, 2002. 103p. ISBN: 8572441719.

$>$ Melo Neto, Francisco Paulo y FROES, César. Responsabilidade social e cidadania empresarial: a administração do terceiro setor. Rio de Janeiro: Qualitymark, 1999. 208 p. ISBN: 8573032405.

> Muylaert, Roberto. Marketing cultural e comunicação dirigida. São Paulo: Globo, 1993. 291 p. ISBN: 8525011541.

> Stoner, James y Freeman, Edward. Administração. Rio de Janeiro: LTC, 1991. 534 p. ISBN: 8521611684.

Recibido: 30/04/2007

Aprobado: 10/06/2007

Arbitrado Anónimamente 